\title{
The Chernobyl pilot site project: Isolation and microscopic characterisation of fuel particles
}

\author{
N. Ahamdach \\ Institut de Portection et de Sûreté Nucléaire, IPSN/DPRE/SERGD/LESTS, \\ BP. 6, 92265 Fontenay-aux-Roses cedex, France
}

\begin{abstract}
A method of fuel particles separation from contaminated soil samples in heavy liquid was developed. Numerous particles have been isolated and characterised by Scanning Electron Microscopy. 14 years after Chernobyl accident $52 \%$ of Cs, $70 \%$ of Eu and Sr and $65 \%$ of Am still are associated with fuel particles. Hence the source term is mainly represented by fuel particles with a mean diameter of $4.17 \mu \mathrm{m}$. The source term consist of 2 types of particles : UO and $\mathrm{ZrUO}$. Zr-U-O fuel particles account for $74 \%$ of the studied particles and showed much higher stability. Therefore the description of Chernobyl source term weathering requires 2 dissolution laws: a first one concerning UO particles with a higher dissolution constant and a second one with a low dissolution constant describing Zr-U-O dissolution.
\end{abstract}

\section{INTRODUCTION}

In the year 1987, following the Chernobyl accident, Site of Temporary Localisation of Radioactive Wastes (STLRW) was created in the "Red Forest" zone. Trenches in the STLRW contain Red Forest materials (upper soil, litter and vegetable debris) contaminated by fuel particles released during the accident. A particular trench (trench 22), namely Chernobyl Pilot Site located at $2.5 \mathrm{~km}$ south west of Chernobyl Nuclear Power Plant, was selected for carrying out experiments to validate radionuclides transport models in soil and aquifer. For that, it is necessary to define the source term. The infiltration of water through the trench induces a weathering of fuel particles and associated radionuclides are mobilised with time. Different laws describing the dissolution process of spent fuel are available in literature [1]. A specific study conducted on Chernobyl fuel particles led to analogous conclusions $[2,3]$. The dissolution process depend on solution composition ( $\mathrm{pH}$, redox) and physico-chemical characteristics of fuel particles: chemical composition, oxidation state and surface. This work was therefore focused on determination of physico-chemical characteristics of fuel particles occurring in the trench. In this study we describe a new method allowing an isolation of fuel particles from soil components. After isolation, the particles are observed by Scanning Electron Microscopy (SEM) in order to determine the size distribution pattern, matrix composition, morphology and structure of fuel particles.

\section{METHODS AND MATERIALS}

\subsection{Soil sampling}

Waste sample from the trench was collected to a depth of $210-220 \mathrm{~cm}$. In this study $15.6 \mathrm{~g}$ of waste were used for isolation of fuel particles by sedimentation in bromoform. Activity levels of gamma emitting radionuclides associated with this soil sample are given in table 1.

Table 1 : Gamma emitting radionuclides activities in trench soil (2000).

\begin{tabular}{|c|c|c|c|c|c|}
\hline & ${ }^{134} \mathrm{Cs}$ & ${ }^{137} \mathrm{Cs}$ & ${ }^{154} \mathrm{Eu}$ & ${ }^{155} \mathrm{Eu}$ & ${ }^{241} \mathrm{Am}$ \\
\hline Activity $(B q / g)$ & $11.7 \pm 0.7$ & $2051 \pm 139$ & $12 \pm 1.7$ & $7.5 \pm 1$ & $19.4 \pm 2.3$ \\
\hline
\end{tabular}

\subsection{Methods}

\subsubsection{Methodologie and Scanning Electron Microscopy}

ln order to separate fuel particles from soil minerals a methodology was developed. This methodology includes three stcps $\left[\frac{1}{4}\right]$ : 
step I : 2-3 $\mathrm{g}$ of soil were dispersed in $30 \mathrm{ml}$ of bromoform (density $=2.88$ ) in plastic tubes (Nalgen, FEP Oak Ridge tube). After centrifugation the majority of soil components (density <2.88) remains on the air/bromoform interface while heavy fraction (fuel particles and heavy minerals of soil) sinks.

step II : After filtration of the heavy fraction, the presence of fuel particles among the numerous heavy minerals present on the filter is confirmed by an $\alpha, \beta, \gamma$ probe (Eurisys) with a sensitive area of $18 \mathrm{~mm}^{2}$ (surface area of the filter is $1590 \mathrm{~mm}^{2}$ ). In the zone where activity was detected, the heavy particles were collected onto sticky double-faced carbon tabs and were mounted onto aluminium stubs.

step III : Aluminium stubs were analysed with Scanning Electron Microscopy (SEM, Hitachi S-3500N) interfaced with an Energy-Dispersive Spectrometer (ISIS 300). SEM analytical conditions are: accelerating voltage- $20 \mathrm{keV}$, working distance- $15 \mathrm{~mm}$. Due to the number of particles expected to be analysed (each stub containing hundreds of particles), it was decided to apply a new automatic system named GunShot, to sort out the fuel particles. The GunShot program carries out automatic searching and chemical classification of particles on standard stubs. The system uses a threshold set-up using a standard to detect particles in a backscattered electron image. Detected particles are classified and can be relocated for detailed manual review and confirmation. For this study, $\mathrm{a}^{22} \mathrm{Ti} /{ }^{83} \mathrm{Bi}$ standard was specially developed.

\subsubsection{Gamma spectrometry}

Gamma emitting radionuclides were determined using Eurisys N-type HPGe detectors with $40 \%$ relative efficiency. The resolution is respectively $0.76 \mathrm{keV}$ and $1.95 \mathrm{keV}$ for $6 \mathrm{keV}$ and $1332 \mathrm{keV}$.

\section{RESULTS AND DISCUSSION}

All fuel particles have been separated from sample and 568 of them have been characterized by Scanning Electron Microscopy. After a residence time in the trench of 14 years a large amount of particles is still present.

\subsection{Chemical composition and morphological description of fuel particles}

Based on X-ray microanalysis results, the particles can be classified into two main types : 1) fuel particles with $\mathrm{UO}_{\mathrm{x}}$ matrix (figure 1a); 2) fuel particles with $\mathrm{Zr}-\mathrm{U}-\mathrm{O}$ matrix (figure 1b).

Among the 568 fuel particles analysed, 150 have an $\mathrm{UO}_{x}$ matrix and 418 have a $\mathrm{Zr}-\mathrm{O}-\mathrm{U}$ matrix. Thus, fuel particles with $\mathrm{Zr}-\mathrm{U}-\mathrm{O}$ matrix account for $74 \%$ of fuel particles in the studied sample. These particles are the result of the interaction between nuclear fuel and zircaloy tubes during melting event at the moment of the accident.
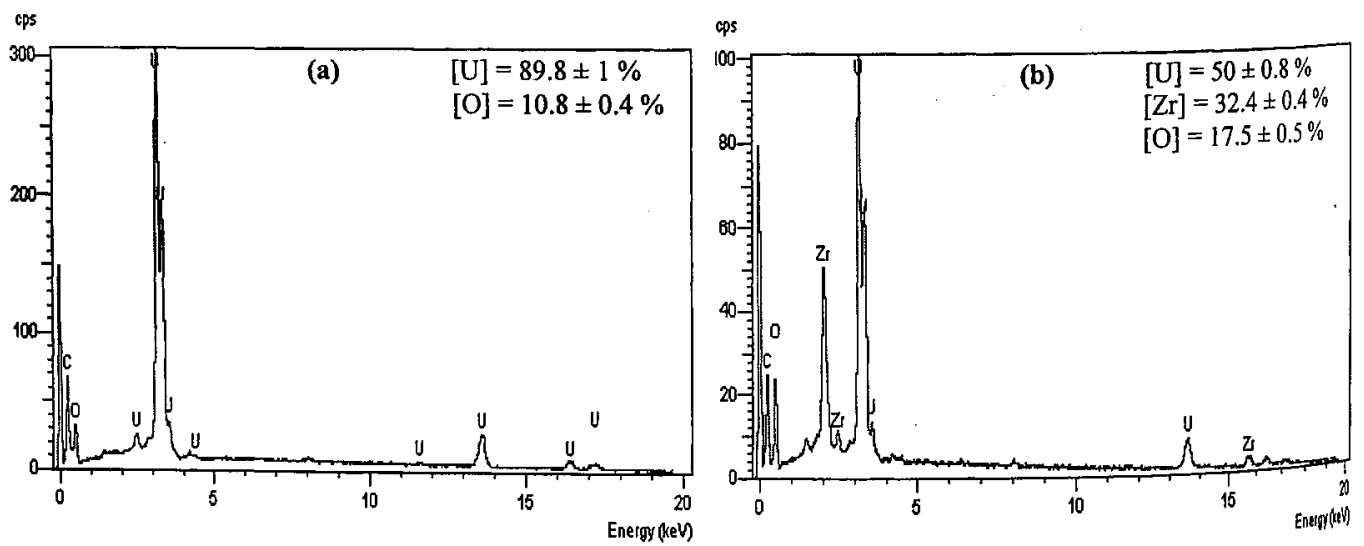

Figure 1: X-ray analysis spectrum and quantitative X-ray analysis of UO fuel particles (a) and Zr-U-O fuel particles (b). 
The morphological peculiarities make it possible to single out the following particles :

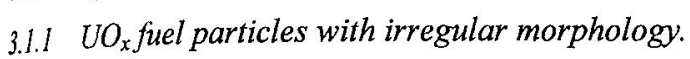

This is the basic type of particles in trench. This type of particles is characterized by the presence of numerous pores already merged together, forming large caverns on the surface (figure 2, photos 1 to 4 ), which may be caused by dissolution in the natural medium.

More rarely, fuel particles with individual microblock structure have been observed (figure 2, photos 5 and 6). These particles represent fragments of unmodified fuel dispersed by the initial explosion. Their shape has been preserved.

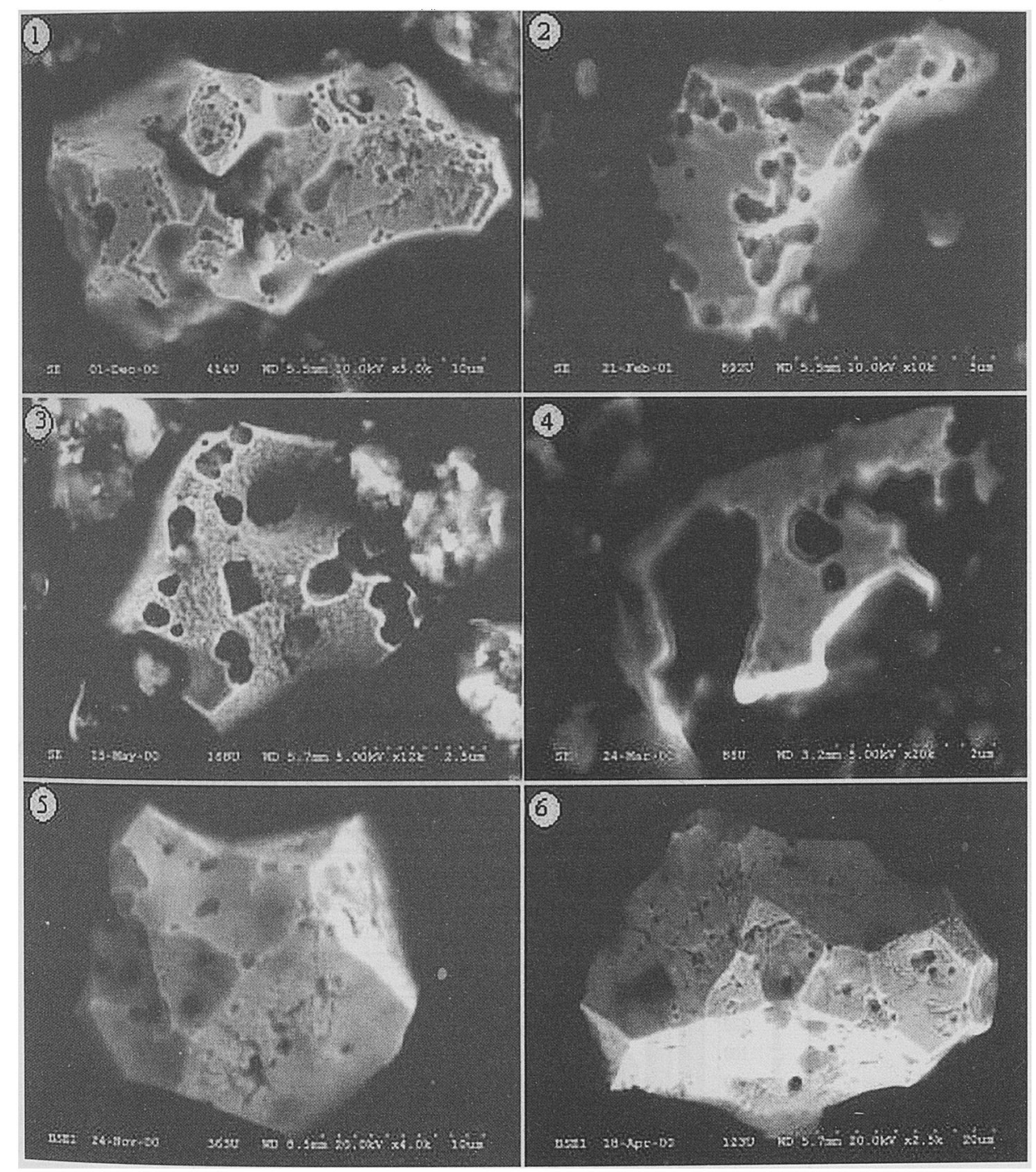

Figure 2 : Microphotograph of $\mathrm{UO}_{\mathrm{x}}$ fuel particles with irregular morphology (photos Ito 4) and individual microblock of unmodified nuclear fuel (photos 5 and 6). 


\subsubsection{Zr-U-O fuel particles with irregular morphology.}

The common characteristic feature of these particles is the presence of melting marks on their surface (figure 3). These particles have probably been in molten state. Some pores can be observed on some particles but their number is lower than in the case of $\mathrm{UO}_{\mathrm{x}}$ particles (figure 3 , photo 3 ).
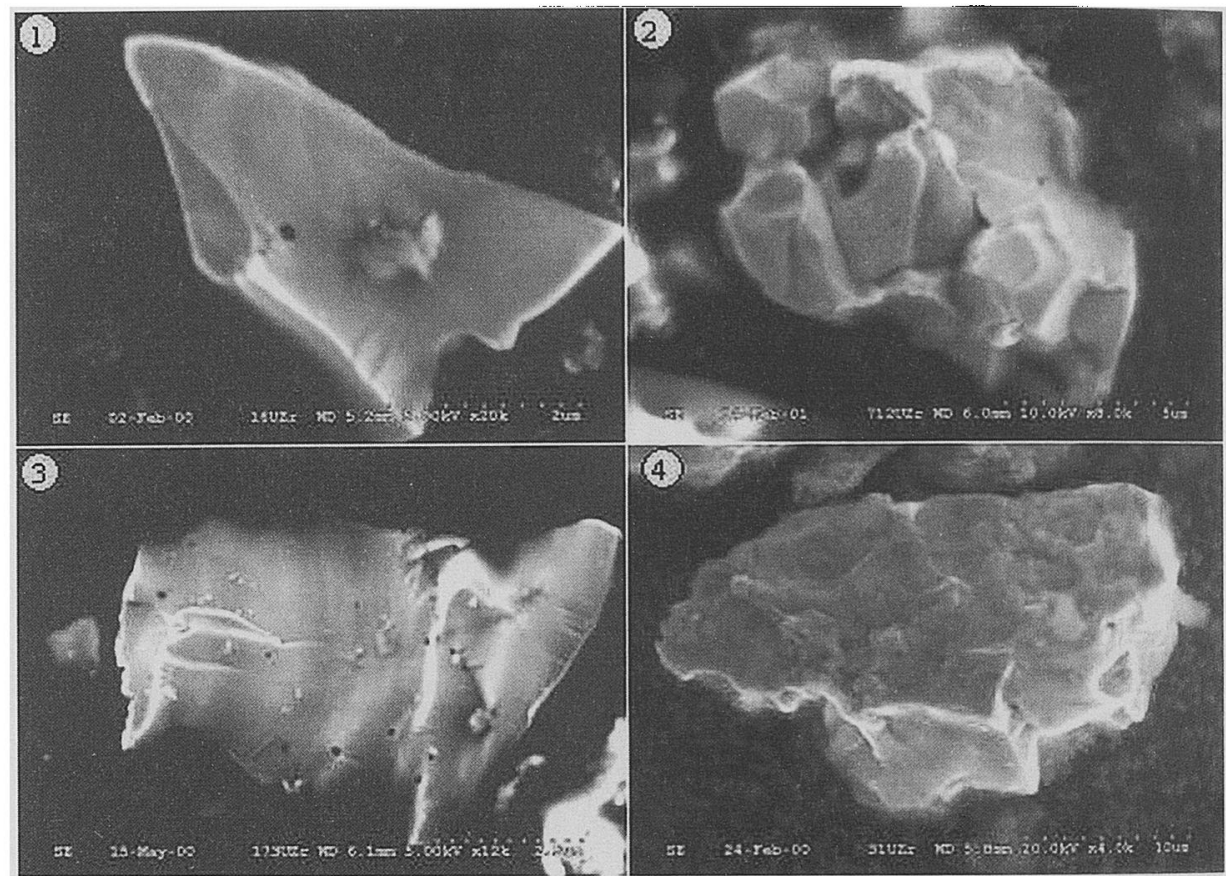

Figure 3: Microphotograph of typical forms of fuel particles with $\mathrm{Zr}-\mathrm{U}-\mathrm{O}$ matrix.

\subsection{Size distribution of fuel particles}

The distribution of fuel particles diameter, assuming they are spherical, determined by SEM is presented in figure 4. The size of $\mathrm{UO}_{\mathrm{x}}$ and $\mathrm{Zr}-\mathrm{U}-\mathrm{O}$ fuel particles vary from 1.1 to $34 \mu \mathrm{m}$ and from 0.8 to $76 \mu \mathrm{m}$ respectively. However, $87 \%$ of $\mathrm{UO}_{\mathrm{x}}$ type and $95 \%$ of $\mathrm{Zr}-\mathrm{U}-\mathrm{O}$ type have a size smaller than $10 \mu \mathrm{m}$.

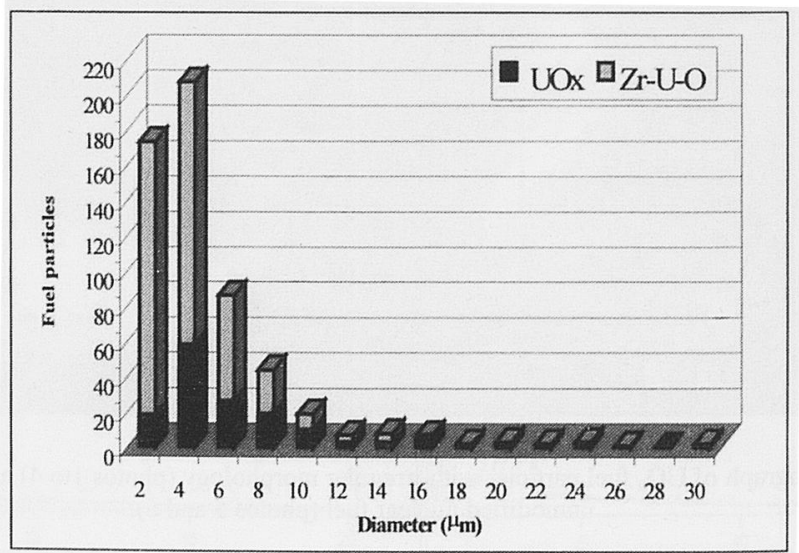

Figure 4 : Size distribution of fuel particles from trench 
The size of fuel particles is assumed to be distributed following a lognormal law :

$f(d)=\frac{1}{\sqrt{2 \pi \cdot s . d}} \exp \left\{-0.5\left[\frac{\ln (\mathrm{d})-\mathrm{m}}{\mathrm{s}}\right]^{2}\right\}$

where

$d=$ diameter of particles $(\mu \mathrm{m})$

$\mathrm{m}=1.15$ (mathematical expectations of particle diameter logarithm)

$\mathrm{s}=0.75$ (mean quadrant deviation of particle diameter logarithm).

The mean diameter of fuel particles is $4.17 \mu \mathrm{m}$ and standard deviation is 3.62 .

Assuming that fuel particles are spherical, we can calculate a specific area of particles from diameter.

Thus, specific area :

$S=\frac{6}{\rho . d}=1308 \mathrm{~cm}^{2} / \mathrm{g}$

$d=$ mean diameter of particles

$p=$ density of fuel $=11 \mathrm{~g} / \mathrm{cm}^{3}$

Specific area determined above is a minimum value. In the case of $\mathrm{UO}_{\mathrm{x}}$ fuel particles, specific area is higher, because of presence of numerous large pores. The dissolution rate depends on the particles surface, therefore the dissolution is more effective for $\mathrm{UO}_{\mathrm{x}}$ particles than for $\mathrm{Zr}-\mathrm{U}-\mathrm{O}$.

\section{3,3 Activity mass balance}

In order to quantify the part of activity associated with fuel particles in trench, gamma activity of sample was determined before separation of fuel particles and after separation. Results show that $52 \%$ of $\mathrm{Cs}, 70$ $\%$ of Eu and $65 \%$ of Am are still associated with fuel particles (table 2). It means that in the trench, source term is mainly represented by fuel particles. The fraction of the total Cs activity associated to fuel particles is lower than those of Eu and Am because of its high volatility during the accident. Temperature reached in a local section of the reactor was $2500-2600{ }^{\circ} \mathrm{C}[5]$.

Table 2 : Ganuma emitting radionuclides activity mass balance in trench waste in 2000.

\begin{tabular}{|c|c|c|c|}
\hline \multirow{2}{*}{ Radionuclides } & \multicolumn{2}{|c|}{ Gamma activity in waste sample (Bq) } & \multirow{2}{*}{$\begin{array}{l}\% \text { of activity } \\
\text { in fuel particles }\end{array}$} \\
\hline & $\begin{array}{l}\text { Activity before fuel } \\
\text { particles separation }\end{array}$ & $\begin{array}{l}\text { Activity after fuel } \\
\text { particles separation }\end{array}$ & \\
\hline${ }^{134} \mathrm{Cs}$ & 183 & 90 & 51 \\
\hline${ }^{137} \mathrm{Cs}$ & 32065 & 15452 & 52 \\
\hline${ }^{154} \mathrm{Eu}$ & 188 & 58 & 69 \\
\hline${ }^{155} \mathrm{Eu}$ & 117 & 35 & 70 \\
\hline${ }^{241} \mathrm{Am}$ & 303 & 107 & 65 \\
\hline
\end{tabular}

${ }^{90} \mathrm{Sr}$ activity associated with fuel particles is calculated using measured activity of ${ }^{154} \mathrm{Eu}$ and activity ratio ${ }^{90} \mathrm{Sr} /{ }^{154} \mathrm{Eu}$ in Chemobyl nuclear fuel $\left({ }^{0} \mathrm{Sr} /{ }^{154} \mathrm{Eu}=72\right.$ in 2000$)$. Results show that $69 \%$ of ${ }^{90} \mathrm{Sr}$ still are associated with fuel particles. 


\section{CONCLUSIONS}

This study has shown that the sedimentation in bromoform liquid is an efficient technique for separation and concentration of fuel particles from contaminated soils. Numerous particles have been isolated and their physico-chemical characteristics were studied by Scanning Electron Microscopy.

$52 \%$ of $\mathrm{Cs}$ activity, $70 \%$ of Eu and $\mathrm{Sr}$ activities and $65 \%$ of Am activity are still associated with fuel particles. Hence 14 years after Chernobyl accident, source term is mainly represented by fuel particles. Assuming that particles are spherical their mean diameter is $4.17 \mu \mathrm{m}$ and therefore calculated specific area is $1308 \mathrm{~cm}^{2} / \mathrm{g}$. The source term consists of two types of fuel particles: One type is composed of $\mathrm{U}$ and $\mathrm{O}$ while the other is composed of $\mathrm{Zr}, \mathrm{U}$, and $\mathrm{O}$. $\mathrm{Zr}-\mathrm{U}-\mathrm{O}$ fuel particles account for $74 \%$ of source term. Scanning electron microscopy, showed that the $\mathrm{UO}_{\mathrm{x}}$ particles have undergone weathering after their deposition while $\mathrm{Zr}-\mathrm{U}-\mathrm{O}$ particles showed much higher stability. This data is in agreement with high stability of natural zircon. Therefore an important part of activity will remain associated to $\mathrm{Zr}$ - $\mathrm{U}-0$ particles. Hence the transfer of mobilised associated radionuclides within the ecosystem will be delayed until weathering takes place.

Model development and modelling results of the spent fuel and Chernobyl fuel particles dissolution process considered that the source term is only made of UO. Therefore, dissolution constants from these models could not be applied to the Chernobyl source term because they would imply an overestimation of assessment of mobilisation, transfer and short term consequences of radionuclide releases. The description of Chernobyl source term weathering requires 2 dissolution laws: a first one concerning UO particles with a higher dissolution constant and a second one with a low dissolution constant describing Zr-U-O dissolution.

\section{Acknowledgments}

The author would like to thanks C. Mallet and J.L. Roujou (IPSN/DPRE/SERGD/LESTS) for technical support.

\section{References}

[1] Grambow et al. Source term for performance assessment of spent fuel as a waste form. Final report, Nuclear Science and Technology, EUR 19140EN.

[2] Kashparov V.A., Protsak V.P., Ahamdach N., Stammose D. , Peres J.M., Yoschenko V.I.Zvarich S.I. J.N.M. 279 (2000) 225-233.

[3] Kashparov V.A., Oughton D. H., Zvarich S.I., Protsak V.P. \& levchuk S. E. Health Physics Volume 76, Number 3 (1999), 251-259.

[4] Ahamdach N. \& Stammose D. CRAS, 330, (2000), 415-422.

[5] Burakov B. E., Anderson E. B., Galkin B. Ya., Pazukhin E. M. \& Shabalev S. I. Radichimica Acta 65, (1994), 199-202. 